\title{
The Role of Humoral and Cell-Mediated Adaptive Immune Response
}

\author{
Tetsuhiro Tanaka1, William G Couser² and Masaomi Nangaku \\ ${ }^{1}$ Division of Nephrology and Endocrinology, University of Tokyo, Tokyo, \\ ${ }^{2}$ Division of Nephrology, Department of Medicine, University of Washington, \\ Washington, \\ ${ }^{1}$ Japan \\ ${ }^{2} U S A$
}

\section{Introduction}

Glomerulonephritis is a major cause of chronic kidney disease worldwide and presents with various histological and clinical manifestations in terms of severity and duration, resulting in diverse clinical outcomes. Immune-mediated injury of the resident glomerular cells plays a critical role in many forms of glomerular injury and mounting evidence indicates that both humoral and cell-mediated mechanisms are involved.

\section{The helper $\mathrm{T}$ cell paradigm}

Studies in the past quarter of century have established a role for lymphocytes in the pathogenesis of immune-mediated glomerular diseases. CD4- expressing T helper cells are a subgroup of $\mathrm{T}$ lymphocytes that provide help for immunoglobulin production and direct cellular immune mechanisms through activation of effector cells, such as macrophages. The role of $\mathrm{T}$ helper cells is variable depending on the nature of disease, and differential activation of $\mathrm{T}$ helper cell subsets has been proposed as one of the plausible explanations for the diversity of injury in glomerular diseases.

The majority of $\mathrm{T}$ helper cells are naïve cells without specified patterns of cytokine production (Th0 cells). Upon stimulation by antigen-presenting cells, such as macrophages and dendritic cells (DC), they receive the signal via their $a / \beta$ T cell receptor (TCR) and differentiate into either T helper 1 (Th1) or T helper 2 (Th2) cells. DC are specialized cells for uptake, transport, processing and presentation of antigens to T cells (Mellman and Steinman 2001), and subsets of DC have been identified that may influence Th1 and Th2 development (Moser and Murphy 2000). They facilitate Th1 differentiation when they are stimulated via toll-like receptors (TLRs), by secreting IL-12, while Th2 differentiation is mediated by IL-4. The cytokine milieu is a key factor in directing Th1 and Th2 polarization.

Differentiated Th1 and Th2 subclasses are functionally distinguished by their specific profiles of cytokine production and their ability to induce different types of effector responses. Th1 cells produce interferon (IFN)- $\gamma$, interleukin (IL)-2 and tumor necrosis factor (TNF)-a. They activate macrophages, induce delayed-type hypersensitivity responses, and 
stimulate B cells to produce complement-fixing antibody isotypes that mediate opsonization and phagocytosis. Th2 cells produce IL-4, IL-5, IL-10 and IL-13 and promote production of non-complement-fixing IgG isotypes and IgE. Therefore, Th1 cells are largely responsible for cell-mediated immunity, while Th2 cells play a central role in humoral immune response.

There is an interaction between the Th1 and the Th2 responses. They inhibit each other by several mechanisms. For example, IFN- $\gamma$ produced in Th1 cells inhibit the expression of CD40 ligand (CD40L) on the surface of Th2 cells and suppress B cell activity. On the other hand, IL-4 and IL-10 from Th2 cells inhibit IFN- $\gamma$ and IL-12 production in Th1 cells.

In the kidney, the Th2-mediated response is characterized by formation of immune complexes and deposition in the glomerulus, which is usually followed by complement activation. On the other hand, the Th1-mediated response is characterized by infiltration of circulating mononuclear cells and crescent formation. Both responses are capable of releasing mediators that are responsible for functional and structural changes as seen in primary glomerular diseases. Importantly, these apparently discrepant mechanisms of immune reactions, the Th1 and Th2 responses, are not always mutually exclusive and operate in a coordinated manner in glomerular injury, depending on etiology and pathological stages.

Recently, Th17 cells were identified as a new subset of T helper cells unrelated to Th1 or Th2 cells. They are a subset of T helper cells characterized by IL-17 production, differentiated from naïve $T$ cells in the presence of both transforming growth factor (TGF)- $\beta$ and IL- 6 in mice, and are implicated in the pathogenesis of experimental allergic encephalomyelitis (EAE) and collagen-induced arthritis (CIA) (Langrish et al. 2005). Evidence suggests that the Th17 response may also pertain to inflammatory and autoimmune diseases in humans, such as rheumatoid arthritis, inflammatory bowel disease and psoriasis. Several cytokines such as IL-21 and IL-23 are involved in regulating activation and differentiation of Th17 cells. In the kidney, Th17 effector cells have been demonstrated in biopsy samples in human glomerulonephritis (Abdulahad et al. 2009) and may participate in the pathogenesis of proliferative glomerulonephritis via production of IL-17 and direct induction of renal inflammation (Kim et al. 2009; Miossec et al. 2009; Turner et al. 2010; Kitching and Holdsworth 2011). Recent studies utilizing genetically engineered mice showed that RORYt promotes the development of crescentic glomerulonephritis by directing nephritogenic Th17 responses (Steinmetz et al. 2011) . In contrast, the adaptive immune response by $\mathrm{T}$ cells is regulated by $\mathrm{T}$ regulatory cell (Treg)s (Jiang and Chess 2006). Treg cells are in charge of suppressing potentially deleterious activities of Th cells. Lyn-deficient mice, which increase titers of autoantibodies with age, develop immune complex-mediated glomerulonephritis, and Tregs are expanding in these mice in an effort to control the autoimmune disease, although they are simply overwhelmed by the disease process eventually (Tsantikos et al. 2009).

\section{Humoral immune response}

Many forms of glomerulonephritis are autoimmune in nature and loss of self-tolerance and exposure to etiologic agents lead to immune-complex formation, presumably by mechanisms of molecular mimicry and epitope spreading. Causative antigens include normal intrinsic structures of the glomerulus (eg. non-collagenous domain of the alpha-III chain of type IV collagen in Goodpasture's syndrome), non-renal self antigens (eg. DNAnucleosome complex in systemic lupus erythematosus (Kalaaji et al. 2007)) or exogenous 
agents (eg. HCV antigen-containing cryoglobulins in hepatitis $\mathrm{C}$ virus-associated membranoproliferative glomerulonephritis (MPGN) (Stehman-Breen and Johnson 1998)). Immune complexes are either formed in the systemic circulation and localize in the glomerulus through passive trapping (eg. serum sickness disease in rabbits) or are formed in situ and form immune deposits locally. In the latter case, an antibody either binds specific antigens intrinsic to the glomerulus, or soluble antigens that become localized due to charge interactions with the glomerular capillary wall or by nonspecific uptake by the mesangium. Identification of responsible antigens in human glomerular diseases, however, is difficult, and multiple antigens and routes leading to immune complex formation appear to co-exist in a single disorder. In poststreptococcal glomerulonephritis (PSGN), for example, several candidate exogenous antigens, such as nephritis-associated plasmin receptor (NAPlr) and Streptococcal pyrogenic exotoxin B (SPE B) have been postulated. In systemic lupus erythematosus (SLE), circulating immune complexes composed of antibodies against double-stranded DNA and ribonucleoproteins are readily detectable, which correlate with disease activity (Izui et al. 1979), and anti-DNA and DNA immune complexes are enriched in kidney eluates (Koffler et al. 1967), leading to speculation that immune deposits are formed in circulation and accumulate in the kidney through passive trapping. However, immune complexes are formed in situ as well, via charge interactions between antibodies and DNA-histone complexes already deposited in the glomerulus (Schmiedeke et al. 1989; van Bruggen et al. 1997; Mortensen and Rekvig 2009; Crispin et al. 2010). Furthermore, some lupus autoantibodies appear to bind directly to intrinsic glomerular antigens.

Deposits are observed in subepithelial (eg. Heymann nephritis model in rats and human membranous nephropathy), subendothelial (eg. type 1 MPGN) and mesangial (eg. IgA nephropathy) spaces. In general, immune complexes formed in situ are more nephritogenic, because they are more capable of activating local complement response (Couser and Salant 1980), releasing vasoactive substances, reactive oxygen species, cytokines and procoagulants (Couser 1998). In fact, it is rather unusual that immunoglobulins themselves induce significant injury in the kidney, except for antibodies against components of the podocyte slit diaphragm (Holthofer 2007).

The complement system is an important mediator of tissue inflammation and injury. It is a family of more than 20 serum and cell-surface proteins and they operate as a cascade of reactions. The IgG immune complexes bind to complement factor $\mathrm{Clq}$ and activate the $\mathrm{C} 1$ complex, leading to the formation of $\mathrm{C} 3$ convertase and the enzymatic cleavage of the central complement component $\mathrm{C} 3$. $\mathrm{C} 3$ then releases the chemotactic factor $\mathrm{C} 3 \mathrm{a}$ and the covalent $\mathrm{C} 3 \mathrm{~b}$ attaches to the host cells, which is an important step for continued activation of the terminal membrane attack complex, C5b-9, and for the amplification through the alternative pathway. C5b-9 is thought to be the key component responsible for the complement-mediated glomerular injury. It inserts in sublytic amounts into the glomerular membranes, triggers cell activation and mediates injury.

The complement cascade is tightly regulated by short half-lives of its components and a series of endogenous regulatory proteins. Complement regulatory proteins counteract the complement activity and protect glomerular cells from injury (Nangaku 1998). In vitro, overexpression of CD59 protected cultured glomerular cells from attack (Nangaku et al. 1996). In the rat Heymann nephritis model, simultaneous blockade of complement regulatory proteins by neutralizing antibodies was required to develop proteinuria following injection of anti-megalin antibody (Schiller et al. 1998). Furthermore, genetic ablation of decay-accelerating factor (DAF) and CD59 aggravated tissue injury in anti-GBM 
nephritis (Sogabe et al. 2001), nephrotoxic nephritis (Lin et al. 2002) and ischemiareperfusion (Yamada et al. 2004) models in mice. In humans, genetic abnormalities of factor $\mathrm{H}$, a soluble complement regulatory protein at the hit point of $\mathrm{C} 3 \mathrm{~b}$, compose approximately 15-30\% of atypical HUS (Rougier et al. 1998; Warwicker et al. 1998; Noris et al. 1999), showing that failure to control intravascular complement activity can lead to endothelial injury, formation of thrombus, and eventually, HUS. Mice genetically deficient for Factor $\mathrm{H}$, as well as pigs with congenital factor H deficiency develop type II MGPN (Pickering et al. 2002), again highlighting the critical relevance of complement regulation in maintaining normal glomerular structure.

\subsection{Heymann nephritis model in the rat}

The role of immune complexes formed in situ has been most extensively studied in the Heymann nephritis model in the rat, a human counterpart of membranous nephropathy $(\mathrm{MN})$. This is a non-proliferative form of GN in which the humoral, Th2 responses play an important role. In human idiopathic MN, an increase in the percentage of IL-4 (Masutani et al. 2004) and IL-10 (Hirayama et al. 2002) was observed in peripheral blood T cells, which correlated with the amount of proteinuria.

Following induction of the disease, antibodies against gp330, megalin (Cavallo 1994; Ronco and Debiec 2005), are deposited at the subepithelial space of the glomerulus and trigger podocyte injury through activation of the complement system, particularly the membrane attack complex, C5b-9. C5b-9 inserts into the podocyte membrane and is then transported across the cell to be extruded into the urinary space, resulting in elevated levels of C5b-9 in the urine (Kerjaschki et al. 1989). C5b-9 is thought to be the major mediator of altered glomerular permeability function, although histologic changes are minimal by light microscopy (Nangaku et al. 2005). Depletion of complement complements using cobra venom factor greatly reduced the amount of proteinuria (Salant et al. 1980; Saran et al. 2003). At the cellular level, C5b-9 generates hydrogen peroxide (Shah 1988; Neale et al. 1993) triggers DNA damage (Pippin et al. 2003), causes reversible disruption of actin microfilaments (Topham et al. 1999), increases the expression of TGF- $\beta$ and its receptors, leading to overproduction of extracellular matrix, GBM thickening and spike formation. It also induces apoptosis in podocytes, dissociation of nephrin from the actin cytoskeleton (Yuan et al. 2002), detachment and excretion in the urine (Cybulsky 2011). However, subepithelial deposits in general induce no inflammation, probably because they are located at a site inaccessible to circulating cells.

Several caveats exist in translating these findings in rats into human MN. First, the responsible antigen, megalin, shows a distinct pattern of spatial distribution among species. In rats, megalin is expressed both on the brush border of proximal tubules and the soles of podocyte foot processes at which immune complexes are initially formed. In humans, however, megalin is only expressed in proximal tubules and not in podocytes, excluding megalin from the list of responsible self-antigens in human MN. Nevertheless, findings obtained from the Heymann nephritis provide solid evidence that some components on the podocyte membrane serve as targets for immune complex formation in situ and trigger cascades of humoral immune responses that lead to massive proteinuria. Second, deposition of immunoglobulin in human $\mathrm{MN}$ is predominantly of the IgG4 subclass, which is theoretically incapable of triggering complement activation. This is in contrast to the fact that complements undoubtedly play an important role in the rat Heymann nephritis. It may be a relevant finding that C6-deficient PVG rats incapable of forming C5b-9 also develop 
massive proteinuria following injection of antisera, suggesting that complementindependent mechanisms may also exist in this model (Spicer et al. 2007).

To date, much effort has been made to identify podocyte antigens responsible for human $\mathrm{MN}$, which are only beginning to be uncovered. Recent breakthrough studies revealed pathogenic antigens of human $\mathrm{MN}$ in podocytes; i.e. neutral endopeptidase (NEP) that causes neonatal MN and phospholipase A2 receptor (PLA2R) that causes adulthood MN.

The proposed mechanisms on the pathogenesis of anti-NEP antibody-mediated neonatal NM was as follows. A genetically NEP-deficient mother developed anti-NEP antibody during the first pregnancy, which was transferred to the second baby not deficient for NEP. As a result, antibody against NEP localized on the surface of podocytes, formed immune complex in situ and subepithelial immune deposits and eventually developed neonatal membranous nephropathy in the second baby (Debiec et al. 2002). Subsequently, families with truncating mutation in the MME gene (coding for NEP) were reported, in which cases second infants born from MME-mutated mothers developed neonatal MN, indicating that the MME gene product is a cause of alloimmunization during pregnancy (Debiec et al. 2004). Clearly, however, NEP is only responsible for a fraction of rare cases of neonatal MN and not likely a universal antigen.

In contrast, serum from approximately $70 \%$ of patients with idiopathic membranous nephropathy recognized a $185 \mathrm{kDa}$ glycoprotein, which was identified as PLA2R by mass spectrometry. Anti-PLA2R antibodies in serum were mainly of IgG4 subclass, the predominant IgG subclass in glomerular deposits. PLA2R was expressed in podocytes of normal human glomeruli and colocalized with IgG4 in subepithelial immune deposits (Beck et al. 2009). These findings were recently supported by independent genomewide association studies of single-nucleotide polymorphisms (SNPs) in patients with idiopathic MN from three populations of white ancestry (Stanescu et al. 2011). The joint analysis of data from the 556 patients studied identified the gene encoding PLA2R as a risk allele of idiopathic MN.

\subsection{Goodpasture's syndrome}

Anti-GBM antibody disease (Goodpasture's syndrome) is a disorder in which circulating antibodies against an antigen intrinsic to the glomerular basement membrane (GBM) cause rapidly progressive glomerulonephritis (RPGN). Non-collagenous domain of the alpha-III chain of type IV collagen (a3IV-NCI) is likely a responsible antigen (Hudson et al. 2003; Hudson 2004), and eluates from patients contain antibodies against a5IV-NCI as well as a3IV-NCI. Of interest, the antigen requires certain quarternary structures to be recognized by the antibody, and the native cross-linked a345IV-NCI escapes recognition (Pedchenko et al. 2010). The disease is primarily initiated through autoantibody-mediated reactions, but an additional role of delayed hypersensitivity reactions is also suggested, because Th1 effector cytokines such as IL-12 and IFN-ץ play important roles in this model (Kitching et al. 2004). Passive transfer of anti-GBM antibodies alone was not sufficient to induce disease in the absence of T cells (Kalluri et al. 1997) and T cells sensitized to the GBM antigen alone were sufficient to initiate injury (Wu et al. 2002). Furthermore, oral administration of a3IV-NCI ameliorated disease (Reynolds and Pusey 2001) and nasal application of this antigen protected from injury, which was associated with suppression of glomerular $\mathrm{T}$ cells and macrophages (Reynolds et al. 2005). These findings suggested the role of systemic suppression of $\mathrm{T}$ cell function in ameliorating disease. In this regard, the possible participation of Tregs is anticipated, but this remains to be proven. 
Goodpasture's syndrome is clinically associated with alveolar hemorrhage. Because the a3IV-NCI is also expressed within the alveolar basement membrane, responsible antibodies recognize alveolar epithelium as well. Immune complexes then cause injury and subsequent effector responses, leading to pulmonary hemorrhage in affected patients.

\subsection{Poststreptococcal glomerulonephritis}

The major pathogenic mechanism of poststreptococcal glomerulonephritis (PSGN) is an in situ immune complex formation due to deposition of streptococcal nephritogenic antigens, such as nephritis-associated plasmin receptor (NAPlr) and Streptococcal pyrogenic exotoxin B (SPE B). Both are capable of activating the alternate pathway of the complement cascade and enhance the expression of adhesion molecules. SPE B also stimulates the production of chemotactic cytokines.

NAPlr was isolated from group A streptococcus and was shown to bind plasmin(ogen). In the original report, 92 percent of Japanese patients with the acute PSGN had anti-NAPlr antibodies, and about $80 \%$ of renal biopsy samples showed deposits of $\mathrm{NaPlr}$, especially in the early stage of the disease, but the deposits did not colocalize with either C3 or IgG. NAPlr exhibits glyceraldehyde-3-phosphate dehydrogenase (GAPDH) activity in vitro. Mechanistically, it is speculated that NAPlr in the mesangium interacts with plasmin(ogen) and causes glomerular injury by degrading GBM through activation of metalloproteinase precursors. Then, circulating immune complexes move across damaged GBM and accumulate in the subepithelial space (Yamakami et al. 2000; Yoshizawa et al. 2004).

SPE B is a cationic cysteine proteinase and was found in 12 of 17 biopsies from patients in Latin America and Switzerland. SPE B deposits localized within the subepithelial electron dense deposits (humps) and colocalized with complement (Batsford et al. 2005). Antibodies to SPE B were detected in the convalescent sera in all patients tested.

To date, it is speculated that separate antigens may be responsible for PSGN in different parts of the world and among patients with distinct genetic backgrounds (Rodriguez-Iturbe and Batsford 2007; Rodriguez-Iturbe and Musser 2008).

\subsection{Immune complex in the subendothelial space and the mesangium}

Immune complexes can be formed and deposited in other compartments of the glomerulus as well. Deposition in the subendothelial space can be found in human type 1 MPGN and lupus nephritis (Class III and IV). They recruit circulating inflammatory cells, such as neutrophils, lymphocytes, macrophages and platelets (Adler and Brady 1999), activate effector responses and cause injury. Local chemotactic factors such as C5a and IL-8 recruit neutrophils to sites of inflammation. There, they phagocytose the immune complex aggregates, become activated and undergo a respiratory burst that generates reactive oxygen species. Macrophages are recruited through interaction with deposited immunoglobulins and by several chemokines, such as macrophage chemoattractant protein1 (MCP-1) and RANTES. Lymphocyte-derived molecules such as macrophage inhibitory factor (MIF) and leukocyte adhesion molecules such as ICAM-1 and VCAM-1 also trigger their migration (Nikolic-Paterson and Atkins 2001). In contrast to neutrophils, they release tissue factors and TGF- $\beta$ and facilitate extracellular matrix accumulation which eventually leads to glomerular sclerosis.

Immune deposits in the mesangium are a representative feature of human IgA nephropathy and lupus nephritis (Class I and II). Following deposit formation, these cells initiate a 
cascade of inflammatory processes, including complement activation, coagulation and release of cytokines and growth factors (Gomez-Guerrero et al. 2005). C5b-9-mediated mechanisms of complement activation are likely to be responsible for immunopathology in the mesangium, too. Furthermore, they undergo a dysregulated increase in proliferation and expansion that lead to glomerular hypercellularity, express markers of de-differentiation such as a-SMA and serve as a source of inflammatory cytokines and growth factors, such as transforming growth factor (TGF)- $\beta$ and platelet-derived growth factor (PDGF) that contribute to glomerular sclerosis.

\section{Cell-mediated immune response}

In the kidney, $\mathrm{T}$ cell-mediated injury occurs primarily through effector responses, such as release of chemokines and recruitment of macrophages and is indispensable for glomerular immunopathology, and available data even suggest that a subset of Th17 cells have effector cell functions alone. On the other hand, some forms of glomerulonephritis do not require immune complexes to develop full-blown pathology. Crescentic glomerulonephritis was produced in a chicken with chemically blocked Bursa of Fabricius, indicating that the lesion was developed without antibody deposits (Bolton et al. 1984). Nephritis was also transferred to normal chickens using only T cells sensitized to GBM (Bolton et al. 1988), and to rats using lymphocytes sensitized to the Goodpasture antigen (Wu et al. 2002). These results indicate that $\mathrm{T}$ cells play important roles in the pathogenesis of certain forms of crescentic nephritis. Cell-mediated immune responses are also critical in several other types of glomerulonephritis, such as minimal change nephrotic syndrome (MCNS), focal and segmental glomerulosclerosis (FSGS), pauci-immune crescentic glomerulonephritis, and lupus (Class IV). Mononuclear cells such as lymphocytes and macrophages are recruited to the glomerulus and release tissue factors and TGF- $\beta$ that initiate fibrin deposition and extracellular matrix accumulation, and there is speculation that $\mathrm{T}$ cells may be the source of permeability factors that contribute to proteinuria and noninflammatory glomerular injury.

\subsection{Glomerular permeability factor(s)}

The initial manifestations in MCNS and FSGS are dramatic increases in glomerular permeability, which are associated with little or no structural abnormality by light microscopy. In these disorders, the presence of non-immunoglobulin circulating permeability factors is postulated, for the following reasons. First, the rapid recurrence of MCNS and FSGS is clinically observed when normal kidneys are transplanted into patients with these disorders (Hoyer et al. 1972). Second, MCNS kidneys demonstrate rapid resolution when placed in a normal environment (Ali et al. 1994). Similarly, a market decrease in proteinuria is observed in some FSGS patients following plasma exchange. Third, serum from recurrent FSGS are able to increase the albumin reflection coefficient of isolated normal glomeruli in vitro (Savin et al. 1996). However, the identity of these permeability factors is elusive and it remains unclear how non-immunoglobulin permeability factors increase glomerular permeability. One study implicated CLC1 as a candidate factor in recurrent FSGS (McCarthy et al. 2010). In contrast, up-regulation of the glomerular expression of angiopoietin-like-4 (Angptl4), a secreted glycoprotein, was shown in the serum and in podocytes in experimental models of MCNS and in the human disease (Clement et al. 2011). A pathogenic role of Angptl4 expression in podocytes was confirmed in genetically engineered animals. 


\subsection{Th1-mediated response in experimental crescentic nephritis}

Severe crescentic injury in the glomerulus, regardless of its underlying cause, is regarded as the result of a Th1 predominant cellular response. It is presumably mediated by T cell- and macrophage- mediated, delayed hypersensitivity responses, which is suggested by the association of cellular immune mediators with local fibrin deposition (Tipping and Holdsworth 2006). Macrophages release ROS and inflammatory cytokines, cause injury in the Bowman's capsule and mediate crescent formation by facilitating compensatory cell growth and influx of inflammatory cells.

\subsubsection{Nephrotoxic nephritis}

Nephrotoxic nephritis is one of the most intensively studied models of experimental glomerulonephritis characterized by cellular proliferation and crescent formation. In this model, nephrotoxic serum is taken up and presented to naïve $\mathrm{T}$ helper cells by antigenpresenting cells, presumably DC. Naïve T cells then differentiate into Th1 effector cells (Schatzmann et al. 1999), which play a central role in the pathogenesis. The first evidence came from a study comparing histological features of injury in Th1 (C57BL6) - and Th2 (BALB/c) - dominant mice (Huang et al. 1997). Studies in Lewis and Brown Norway rats also demonstrated features of cell-mediated types of glomerular injury, which were accompanied by a Th1 polarized profile of cytokine production (Coelho et al. 1997). Analysis of cytokine profiles from biopsies of proliferative glomerulonephritis showed higher levels of IL-2 and IFN- $\gamma$, as compared to non-proliferative forms (Kim et al. 2001). In addition, studies in human anti-GBM glomerular disease supported a role for Th1 responses in injury, by demonstrating IFN- $\gamma$-predominant effector cell responses in active disease and IL-10 predominance in remission (Cairns et al. 2003).

Cytokines produced in response to Th1 polarization play an essential role for crescent formation. Glomerular $\mathrm{T}$ cell and macrophage accumulation was attenuated in mice with genetic deletion of Th1 cytokines, such as IL-12 (Kitching et al. 2000), IFN-ץ (Kitching et al. 1999) and TNF (Timoshanko et al. 2003), which was associated with amelioration of crescentic injury. Conversely, administration of IL-12 augmented Th1 responses and crescentic nephritis (Kitching et al. 1999). On the other hand, Th2 cytokines attenuated proliferative and crescentic nephritis. Mice genetically deficient for IL-4 or IL-10 showed more pronounced Th1 responses and developed more severe crescentic nephritis (Kitching et al. 1998). Conversely, overexpression of IL-10 by gene transfer attenuated crescentic nephritis in Wistar Kyoto rats (Higuchi et al. 2003).

Not all Th1 predominant cytokines, however, behave in a similar way to augment injury, because discrepant results also exist for the role of IFN- $\gamma$, reporting ameliorating effect in nephrotoxic nephritis (Ring et al. 1999), and experimental anti-GBM nephritis (Kitching et al. 2004), suggesting the complex role of IFN-ץ beyond the principle of simple Th1/Th2 predominancy. The cellular source and the co-producition of additional cytokines, such as IL-10, may determine whether IFN- $\gamma$ is protective or harmful (Trinchieri 2007). Similarly, deficiency for IL-13, a Th2-associated cytokine, failed to aggravate nephrotoxic nephritis, despite augmented production of Th1-associated immunoglobulin subclasses (Kitching et al. 2004), leading to speculation that the pathogenic role of Th1-mediated delayed hypersensitivity reactions overweigh that of antibody-mediated immune responses.

DC are remarkably abundant in the tubulointerstitium in the normal kidney. However, DC form periglomerular infiltrates around inflamed glomeruli in nephrotoxic nephritis (Kruger 
et al. 2004), the rat anti-GBM model (Fujinaka et al. 2007) and some forms of human glomerular diseases, such as Wegener's granulomatosus and IgA nephropathy (MarkovicLipkovski et al. 1990). Functionally, dendritic cells appear to have a protective role against injury, by interacting with Th1 cells locally and producing IL-10, thereby suppressing Th1 cell and macrophage functions. When DC were depleted, nephrotoxic nephritis was aggravated. (Scholz et al. 2008).

\subsubsection{Other forms of crescentic glomerulopathies}

A predominant role for Th1 responses has been described in other types of crescentic glomerular diseases as well. In ANCA-associated nephritis, $\mathrm{T}$ cells and macrophages accumulate in glomerular lesions (Cunningham et al. 1999) and glomerular biopsies show high IFN- $\gamma$ and low IL-4 mRNA expression, suggesting a Th-1 predominant effector response. Peripheral blood T cells showed a high IFN- $\gamma:$ IL-4 ratio as compared to nonproliferative forms (Masutani et al. 2003). There is also evidence suggesting the involvement of Th17 responses. Th17 cells promoted autoimmune anti-myeloperoxidase glomerulonephritis in mice (Gan et al. 2010) and patients with ANCA-associated vasculitis had elevated serum levels of IL-17 and IL-23 (Nogueira et al. 2010). It remains unclear, however, how the co-existing Th1 and Th17 responses cross-regulate each other. Available evidence suggests both synergism (O'Connor et al. 2008) and inhibition (Yi et al. 2008). In active Wegener's granulomatosis, peripheral blood T cells produced high levels of IFN- $\gamma$ and monocytes produced high IL-12 regardless of disease activity (Ludviksson et al. 1998). Analysis of cytokine profiles in lesions from the nasal mucosa have yielded conflicting results, and both IL-2 and CCR5+ (Th1) and IL-4 and CCR3+ (Th2) cells were present in renal tissues (Balding et al. 2001).

Human lupus nephritis displays heterogenous patterns of Th1 and Th2 responses, which are probably associated with diverse histopathogolical presentations of this disease entity. In patients with WHO class IV crescentic disease, however, increases in peripheral blood T cell

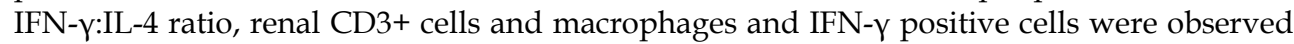
compared to patients with either WHO class V or mild glomerular lesions (Masutani et al. 2001). Th1 cytokine predominance was also shown in the urinary sediment of patients with active lupus nephritis (Chan et al. 2003). Murine models of lupus nephritis are also critically dependent on $\mathrm{T}$ helper cells, in addition to the almost certain dependency on $\mathrm{B}$ cells (Reininger et al. 1996; Chan et al. 1999). Depletion of CD4+ cells attenuated disease in MRLlpr mice (Jabs et al. 1992), in New Zealand black/white (NZB/NZW) mice (Connolly et al. 1992) and in Y-chromosome-associated lupus mice (Lawson et al. 2001). In MRL/lpr mice, however, cytokine profiling showed conflicting results in terms of Th1 (Takahashi et al. 1996; Kikawada et al. 2003) and Th2 (Santiago et al. 1997) predominancy, again refleting the multifactorial nature of the disease.

A fraction of cases with IgA nephropathy also present with proliferative, crescentic lesions. In general, this is a disease with heterogeneity of Th responses. The onset may be related to factors favoring a Th2-predominnat environment that promotes dysregulated $\operatorname{IgA}$ production, but a severe proliferative disease is associated with Th1 predominant responses. This idea is supported by experimental observation that adoptive transfer of $\mathrm{T}$ helper cells alone was unable to initiate disease (Suzuki et al. 2007). Meanwhile, IL-12 induced glomerular crescents and macrophage accumulation in a ddY strain with high $\operatorname{IgA}$, suggesting a role of Th1 subsets (Nogaki et al. 2000). 


\section{Conclusion}

Immune-mediated mechanisms of injury are involved in a variety of primary glomerular diseases. In humoral immune injury, immune complexes against intrinsic renal antigens, exogenous agents and non-renal, self antigens are either formed in situ or are passively trapped in the glomerulus. Immune deposits then trigger injury by activating the complement cascade, releasing oxidants, cytokines and growth factors and recruiting effector cells. The membrane attack complex, C5b-9 plays a critical role in the majority of humoral responses in the kidney. On the other hand, proliferative, crescentic glomerulonephritis is almost always associated with cell-mediated immune responses, which are associated with effector cell activation such as macrophages and release of cytokines and growth factors, leading to delayed hypersensitivity response. Th1 cytokines, such as IFN- $\gamma$ and IL-12 play important roles during the pathogenesis. The Th17 responses may also participate in cell-mediated injury in some forms of glomerulopathies, such as ANCA-associated nephritis. The humoral and cell-mediated mechanisms of injury are not necessarily exclusive, mutually, but play respective roles at each stage of a given disease category, depending on its nature. The critical, albeit complex, participation of both humoral and cell-mediated immune responses provides rationale for the current treatment strategies that target modulation of immunopathogenesis at multiple stages of glomerular injury.

\section{References}

Abdulahad, W. H., C. A. Stegeman, et al. (2009). "Review article: The role of CD4(+) T cells in ANCA-associated systemic vasculitis." Nephrology (Carlton) 14(1): 26-32.

Adler, S. and H. R. Brady (1999). "Cell adhesion molecules and the glomerulopathies." Am J Med 107(4): 371-86.

Ali, A. A., E. Wilson, et al. (1994). "Minimal-change glomerular nephritis. Normal kidneys in an abnormal environment?" Transplantation 58(7): 849-52.

Balding, C. E., A. J. Howie, et al. (2001). "Th2 dominance in nasal mucosa in patients with Wegener's granulomatosis." Clin Exp Immunol 125(2): 332-9.

Batsford, S. R., S. Mezzano, et al. (2005). "Is the nephritogenic antigen in post-streptococcal glomerulonephritis pyrogenic exotoxin B (SPE B) or GAPDH?" Kidney Int 68(3): 1120-9.

Beck, L. H., Jr., R. G. Bonegio, et al. (2009). "M-type phospholipase A2 receptor as target antigen in idiopathic membranous nephropathy." N Engl J Med 361(1): 11-21.

Bolton, W. K., M. Chandra, et al. (1988). "Transfer of experimental glomerulonephritis in chickens by mononuclear cells." Kidney Int 34(5): 598-610.

Bolton, W. K., F. L. Tucker, et al. (1984). "New avian model of experimental glomerulonephritis consistent with mediation by cellular immunity. Nonhumorally mediated glomerulonephritis in chickens." J Clin Invest 73(5): 1263-76.

Cairns, L. S., R. G. Phelps, et al. (2003). "The fine specificity and cytokine profile of T-helper cells responsive to the alpha3 chain of type IV collagen in Goodpasture's disease." J Am Soc Nephrol 14(11): 2801-12.

Cavallo, T. (1994). "Membranous nephropathy. Insights from Heymann nephritis." Am J Pathol 144(4): 651-8. 
Chan, O. T., M. P. Madaio, et al. (1999). "B cells are required for lupus nephritis in the polygenic, Fas-intact MRL model of systemic autoimmunity." J Immunol 163(7): 3592-6.

Chan, R. W., L. S. Tam, et al. (2003). "Inflammatory cytokine gene expression in the urinary sediment of patients with lupus nephritis." Arthritis Rheum 48(5): 1326-31.

Clement, L. C., C. Avila-Casado, et al. (2011). "Podocyte-secreted angiopoietin-like-4 mediates proteinuria in glucocorticoid-sensitive nephrotic syndrome." Nat Med 17(1): 117-22.

Coelho, S. N., S. Saleem, et al. (1997). "Immunologic determinants of susceptibility to experimental glomerulonephritis: role of cellular immunity." Kidney Int 51(3): 64652.

Connolly, K., J. R. Roubinian, et al. (1992). "Development of murine lupus in CD4-depleted NZB/NZW mice. Sustained inhibition of residual CD4+ $\mathrm{T}$ cells is required to suppress autoimmunity." J Immunol 149(9): 3083-8.

Couser, W. G. (1998). "Pathogenesis of glomerular damage in glomerulonephritis." Nephrol Dial Transplant 13 Suppl 1: 10-5.

Couser, W. G. and D. J. Salant (1980). "In situ immune complex formation and glomerular injury." Kidney Int 17(1): 1-13.

Crispin, J. C., S. N. Liossis, et al. (2010). "Pathogenesis of human systemic lupus erythematosus: recent advances." Trends Mol Med 16(2): 47-57.

Cunningham, M. A., X. R. Huang, et al. (1999). "Prominence of cell-mediated immunity effectors in "pauci-immune" glomerulonephritis." J Am Soc Nephrol 10(3): 499-506.

Cybulsky, A. V. (2011). "Membranous nephropathy." Contrib Nephrol 169: 107-25.

Debiec, H., V. Guigonis, et al. (2002). "Antenatal membranous glomerulonephritis due to anti-neutral endopeptidase antibodies." N Engl J Med 346(26): 2053-60.

Debiec, H., J. Nauta, et al. (2004). "Role of truncating mutations in MME gene in fetomaternal alloimmunisation and antenatal glomerulopathies." Lancet 364(9441): 1252-9.

Fujinaka, H., M. Nameta, et al. (2007). "Periglomerular accumulation of dendritic cells in rat crescentic glomerulonephritis." J Nephrol 20(3): 357-63.

Gan, P. Y., O. M. Steinmetz, et al. (2010). "Th17 cells promote autoimmune antimyeloperoxidase glomerulonephritis." J Am Soc Nephrol 21(6): 925-31.

Gomez-Guerrero, C., P. Hernandez-Vargas, et al. (2005). "Mesangial cells and glomerular inflammation: from the pathogenesis to novel therapeutic approaches." Curr Drug Targets Inflamm Allergy 4(3): 341-51.

Higuchi, N., H. Maruyama, et al. (2003). "Hydrodynamics-based delivery of the viral interleukin-10 gene suppresses experimental crescentic glomerulonephritis in Wistar-Kyoto rats." Gene Ther 10(16): 1297-310.

Hirayama, K., I. Ebihara, et al. (2002). "Predominance of type-2 immune response in idiopathic membranous nephropathy. Cytoplasmic cytokine analysis." Nephron 91(2): 255-61.

Holthofer, H. (2007). "Molecular architecture of the glomerular slit diaphragm: lessons learnt for a better understanding of disease pathogenesis." Nephrol Dial Transplant 22(8): 2124-8.

Hoyer, J. R., R. L. Vernier, et al. (1972). "Recurrence of idiopathic nephrotic syndrome after renal transplantation." Lancet 2(7773): 343-8. 
Huang, X. R., P. G. Tipping, et al. (1997). "Th1 responsiveness to nephritogenic antigens determines susceptibility to crescentic glomerulonephritis in mice." Kidney Int 51(1): 94-103.

Hudson, B. G. (2004). "The molecular basis of Goodpasture and Alport syndromes: beacons for the discovery of the collagen IV family." J Am Soc Nephrol 15(10): 2514-27.

Hudson, B. G., K. Tryggvason, et al. (2003). "Alport's syndrome, Goodpasture's syndrome, and type IV collagen." N Engl J Med 348(25): 2543-56.

Izui, S., P. J. McConahey, et al. (1979). "Association of circulating retroviral gp70-anti-gp70 immune complexes with murine systemic lupus erythematosus." J Exp Med 149(5): 1099-116.

Jabs, D. A., C. L. Burek, et al. (1992). "Anti-CD4 monoclonal antibody therapy suppresses autoimmune disease in MRL/Mp-lpr/lpr mice." Cell Immunol 141(2): 496-507.

Jiang, H. and L. Chess (2006). "Regulation of immune responses by T cells." N Engl J Med 354(11): 1166-76.

Kalaaji, M., K. A. Fenton, et al. (2007). "Glomerular apoptotic nucleosomes are central target structures for nephritogenic antibodies in human SLE nephritis." Kidney Int 71(7): 664-72.

Kalluri, R., T. M. Danoff, et al. (1997). "Susceptibility to anti-glomerular basement membrane disease and Goodpasture syndrome is linked to MHC class II genes and the emergence of T cell-mediated immunity in mice." J Clin Invest 100(9): 2263-75.

Kerjaschki, D., M. Schulze, et al. (1989). "Transcellular transport and membrane insertion of the C5b-9 membrane attack complex of complement by glomerular epithelial cells in experimental membranous nephropathy." J Immunol 143(2): 546-52.

Kikawada, E., D. M. Lenda, et al. (2003). "IL-12 deficiency in MRL-Fas(lpr) mice delays nephritis and intrarenal IFN-gamma expression, and diminishes systemic pathology." J Immunol 170(7): 3915-25.

Kim, A. H., M. A. Markiewicz, et al. (2009). "New roles revealed for T cells and DCs in glomerulonephritis." J Clin Invest 119(5): 1074-6.

Kim, Y. S., S. Zheng, et al. (2001). "Differential expression of various cytokine and chemokine genes between proliferative and non-proliferative glomerulonephritides." Clin Nephrol 56(3): 199-206.

Kitching, A. R. and S. R. Holdsworth (2011). "The emergence of TH17 cells as effectors of renal injury." J Am Soc Nephrol 22(2): 235-8.

Kitching, A. R., S. R. Holdsworth, et al. (1999). "IFN-gamma mediates crescent formation and cell-mediated immune injury in murine glomerulonephritis." J Am Soc Nephrol 10(4): 752-9.

Kitching, A. R., P. G. Tipping, et al. (1999). "IL-12 directs severe renal injury, crescent formation and Th1 responses in murine glomerulonephritis." Eur J Immunol 29(1): $1-10$.

Kitching, A. R., P. G. Tipping, et al. (2000). "IL-18 has IL-12-independent effects in delayedtype hypersensitivity: studies in cell-mediated crescentic glomerulonephritis." J Immunol 165(8): 4649-57.

Kitching, A. R., P. G. Tipping, et al. (1998). "Interleukin-4 deficiency enhances Th1 responses and crescentic glomerulonephritis in mice." Kidney Int 53(1): 112-8. 
Kitching, A. R., A. L. Turner, et al. (2004). "Experimental autoimmune anti-glomerular basement membrane glomerulonephritis: a protective role for IFN-gamma." J Am Soc Nephrol 15(7): 1764-74.

Kitching, A. R., A. L. Turner, et al. (2004). "Endogenous IL-13 limits humoral responses and injury in experimental glomerulonephritis but does not regulate Th1 cell-mediated crescentic glomerulonephritis." J Am Soc Nephrol 15(9): 2373-82.

Koffler, D., P. H. Schur, et al. (1967). "Immunological studies concerning the nephritis of systemic lupus erythematosus." J Exp Med 126(4): 607-24.

Kruger, T., D. Benke, et al. (2004). "Identification and functional characterization of dendritic cells in the healthy murine kidney and in experimental glomerulonephritis." J Am Soc Nephrol 15(3): 613-21.

Langrish, C. L., Y. Chen, et al. (2005). "IL-23 drives a pathogenic T cell population that induces autoimmune inflammation." J Exp Med 201(2): 233-40.

Lawson, B. R., S. I. Koundouris, et al. (2001). "The role of alpha beta+ T cells and homeostatic T cell proliferation in Y-chromosome-associated murine lupus." J Immunol 167(4): 2354-60.

Lin, F., S. N. Emancipator, et al. (2002). "Decay-accelerating factor confers protection against complement-mediated podocyte injury in acute nephrotoxic nephritis." Lab Invest 82(5): 563-9.

Ludviksson, B. R., M. C. Sneller, et al. (1998). "Active Wegener's granulomatosis is associated with HLA-DR+ CD4+ T cells exhibiting an unbalanced Th1-type T cell cytokine pattern: reversal with IL-10." J Immunol 160(7): 3602-9.

Markovic-Lipkovski, J., C. A. Muller, et al. (1990). "Association of glomerular and interstitial mononuclear leukocytes with different forms of glomerulonephritis." Nephrol Dial Transplant 5(1): 10-7.

Masutani, K., M. Akahoshi, et al. (2001). "Predominance of Th1 immune response in diffuse proliferative lupus nephritis." Arthritis Rheum 44(9): 2097-106.

Masutani, K., M. Taniguchi, et al. (2004). "Up-regulated interleukin-4 production by peripheral T-helper cells in idiopathic membranous nephropathy." Nephrol Dial Transplant 19(3): 580-6.

Masutani, K., M. Tokumoto, et al. (2003). "Strong polarization toward Th1 immune response in ANCA-associated glomerulonephritis." Clin Nephrol 59(6): 395-405.

McCarthy, E. T., M. Sharma, et al. (2010). "Circulating permeability factors in idiopathic nephrotic syndrome and focal segmental glomerulosclerosis." Clin J Am Soc Nephrol 5(11): 2115-21.

Mellman, I. and R. M. Steinman (2001). "Dendritic cells: specialized and regulated antigen processing machines." Cell 106(3): 255-8.

Miossec, P., T. Korn, et al. (2009). "Interleukin-17 and type 17 helper T cells." N Engl J Med 361(9): 888-98.

Mortensen, E. S. and O. P. Rekvig (2009). "Nephritogenic potential of anti-DNA antibodies against necrotic nucleosomes." J Am Soc Nephrol 20(4): 696-704.

Moser, M. and K. M. Murphy (2000). "Dendritic cell regulation of TH1-TH2 development." Nat Immunol 1(3): 199-205.

Nangaku, M. (1998). "Complement regulatory proteins in glomerular diseases." Kidney Int 54(5): 1419-28. 
Nangaku, M., R. L. Meek, et al. (1996). "Transfected CD59 protects mesangial cells from injury induced by antibody and complement." Kidney Int 50(1): 257-66.

Nangaku, M., S. J. Shankland, et al. (2005). "Cellular response to injury in membranous nephropathy." J Am Soc Nephrol 16(5): 1195-204.

Neale, T. J., R. Ullrich, et al. (1993). "Reactive oxygen species and neutrophil respiratory burst cytochrome b558 are produced by kidney glomerular cells in passive Heymann nephritis." Proc Natl Acad Sci U S A 90(8): 3645-9.

Nikolic-Paterson, D. J. and R. C. Atkins (2001). "The role of macrophages in glomerulonephritis." Nephrol Dial Transplant 16 Suppl 5: 3-7.

Nogaki, F., E. Muso, et al. (2000). "Interleukin 12 induces crescentic glomerular lesions in a high IgA strain of ddY mice, independently of changes in IgA deposition." Nephrol Dial Transplant 15(8): 1146-54.

Nogueira, E., S. Hamour, et al. (2010). "Serum IL-17 and IL-23 levels and autoantigenspecific Th17 cells are elevated in patients with ANCA-associated vasculitis." Nephrol Dial Transplant 25(7): 2209-17.

Noris, M., P. Ruggenenti, et al. (1999). "Hypocomplementemia discloses genetic predisposition to hemolytic uremic syndrome and thrombotic thrombocytopenic purpura: role of factor $\mathrm{H}$ abnormalities. Italian Registry of Familial and Recurrent Hemolytic Uremic Syndrome/Thrombotic Thrombocytopenic Purpura." J Am Soc Nephrol 10(2): 281-93.

O'Connor, R. A., C. T. Prendergast, et al. (2008). "Cutting edge: Th1 cells facilitate the entry of Th17 cells to the central nervous system during experimental autoimmune encephalomyelitis." J Immunol 181(6): 3750-4.

Pedchenko, V., O. Bondar, et al. (2010). "Molecular architecture of the Goodpasture autoantigen in anti-GBM nephritis." N Engl J Med 363(4): 343-54.

Pickering, M. C., H. T. Cook, et al. (2002). "Uncontrolled C3 activation causes membranoproliferative glomerulonephritis in mice deficient in complement factor H." Nat Genet 31(4): 424-8.

Pippin, J. W., R. Durvasula, et al. (2003). "DNA damage is a novel response to sublytic complement C5b-9-induced injury in podocytes." J Clin Invest 111(6): 877-85.

Reininger, L., T. H. Winkler, et al. (1996). "Intrinsic B cell defects in NZB and NZW mice contribute to systemic lupus erythematosus in (NZB x NZW)F1 mice." J Exp Med 184(3): 853-61.

Reynolds, J., E. I. Prodromidi, et al. (2005). "Nasal administration of recombinant rat alpha3(IV)NC1 prevents the development of experimental autoimmune glomerulonephritis in the WKY rat." J Am Soc Nephrol 16(5): 1350-9.

Reynolds, J. and C. D. Pusey (2001). "Oral administration of glomerular basement membrane prevents the development of experimental autoimmune glomerulonephritis in the WKY rat." J Am Soc Nephrol 12(1): 61-70.

Ring, G. H., Z. Dai, et al. (1999). "Increased susceptibility to immunologically mediated glomerulonephritis in IFN-gamma-deficient mice." J Immunol 163(4): 2243-8.

Rodriguez-Iturbe, B. and S. Batsford (2007). "Pathogenesis of poststreptococcal glomerulonephritis a century after Clemens von Pirquet." Kidney Int 71(11): 1094104.

Rodriguez-Iturbe, B. and J. M. Musser (2008). "The current state of poststreptococcal glomerulonephritis." J Am Soc Nephrol 19(10): 1855-64. 
Ronco, P. and H. Debiec (2005). "Molecular pathomechanisms of membranous nephropathy: from Heymann nephritis to alloimmunization." J Am Soc Nephrol 16(5): 1205-13.

Rougier, N., M. D. Kazatchkine, et al. (1998). "Human complement factor H deficiency associated with hemolytic uremic syndrome." J Am Soc Nephrol 9(12): 2318-26.

Salant, D. J., S. Belok, et al. (1980). "A new role for complement in experimental membranous nephropathy in rats." J Clin Invest 66(6): 1339-50.

Santiago, M. L., L. Fossati, et al. (1997). "Interleukin-4 protects against a genetically linked lupus-like autoimmune syndrome." J Exp Med 185(1): 65-70.

Saran, A. M., H. Yuan, et al. (2003). "Complement mediates nephrin redistribution and actin dissociation in experimental membranous nephropathy." Kidney Int 64(6): 2072-8.

Savin, V. J., R. Sharma, et al. (1996). "Circulating factor associated with increased glomerular permeability to albumin in recurrent focal segmental glomerulosclerosis." N Engl J Med 334(14): 878-83.

Schatzmann, U., C. Haas, et al. (1999). "A Th1 response is essential for induction of crescentic glomerulonephritis in mice." Kidney Blood Press Res 22(3): 135-9.

Schiller, B., C. He, et al. (1998). "Inhibition of complement regulation is key to the pathogenesis of active Heymann nephritis." J Exp Med 188(7): 1353-8.

Schmiedeke, T. M., F. W. Stockl, et al. (1989). "Histones have high affinity for the glomerular basement membrane. Relevance for immune complex formation in lupus nephritis." J Exp Med 169(6): 1879-94.

Scholz, J., V. Lukacs-Kornek, et al. (2008). "Renal dendritic cells stimulate IL-10 production and attenuate nephrotoxic nephritis." J Am Soc Nephrol 19(3): 527-37.

Shah, S. V. (1988). "Evidence suggesting a role for hydroxyl radical in passive Heymann nephritis in rats." Am J Physiol 254(3 Pt 2): F337-44.

Sogabe, H., M. Nangaku, et al. (2001). "Increased susceptibility of decay-accelerating factor deficient mice to anti-glomerular basement membrane glomerulonephritis." J Immunol 167(5): 2791-7.

Spicer, S. T., G. T. Tran, et al. (2007). "Induction of passive Heymann nephritis in complement component 6-deficient PVG rats." J Immunol 179(1): 172-8.

Stanescu, H. C., M. Arcos-Burgos, et al. (2011). "Risk HLA-DQA1 and PLA(2)R1 alleles in idiopathic membranous nephropathy." N Engl J Med 364(7): 616-26.

Stehman-Breen, C. and R. J. Johnson (1998). "Hepatitis C virus-associated glomerulonephritis." Adv Intern Med 43: 79-97.

Steinmetz, O. M., S. A. Summers, et al. (2011). "The Th17-defining transcription factor RORgammat promotes glomerulonephritis." J Am Soc Nephrol 22(3): 472-83.

Suzuki, H., Y. Suzuki, et al. (2007). "Th1 polarization in murine IgA nephropathy directed by bone marrow-derived cells." Kidney Int 72(3): 319-27.

Takahashi, S., L. Fossati, et al. (1996). "Imbalance towards Th1 predominance is associated with acceleration of lupus-like autoimmune syndrome in MRL mice." J Clin Invest 97(7): 1597-604.

Timoshanko, J. R., J. D. Sedgwick, et al. (2003). "Intrinsic renal cells are the major source of tumor necrosis factor contributing to renal injury in murine crescentic glomerulonephritis." J Am Soc Nephrol 14(7): 1785-93.

Tipping, P. G. and S. R. Holdsworth (2006). "T cells in crescentic glomerulonephritis." J Am Soc Nephrol 17(5): 1253-63. 
Topham, P. S., S. A. Haydar, et al. (1999). "Complement-mediated injury reversibly disrupts glomerular epithelial cell actin microfilaments and focal adhesions." Kidney Int 55(5): 1763-75.

Trinchieri, G. (2007). "Interleukin-10 production by effector T cells: Th1 cells show self control." J Exp Med 204(2): 239-43.

Tsantikos, E., C. Quilici, et al. (2009). "Perturbation of the CD4 T cell compartment and expansion of regulatory $\mathrm{T}$ cells in autoimmune-prone Lyn-deficient mice." J Immunol 183(4): 2484-94.

Turner, J. E., H. J. Paust, et al. (2010). "The Th17 immune response in renal inflammation." Kidney Int 77(12): 1070-5.

van Bruggen, M. C., C. Kramers, et al. (1997). "Nucleosomes and histones are present in glomerular deposits in human lupus nephritis." Nephrol Dial Transplant 12(1): 5766.

Warwicker, P., T. H. Goodship, et al. (1998). "Genetic studies into inherited and sporadic hemolytic uremic syndrome." Kidney Int 53(4): 836-44.

Wu, J., J. Hicks, et al. (2002). "CD4(+) T cells specific to a glomerular basement membrane antigen mediate glomerulonephritis." J Clin Invest 109(4): 517-24.

Yamada, K., T. Miwa, et al. (2004). "Critical protection from renal ischemia reperfusion injury by CD55 and CD59." J Immunol 172(6): 3869-75.

Yamakami, K., N. Yoshizawa, et al. (2000). "The potential role for nephritis-associated plasmin receptor in acute poststreptococcal glomerulonephritis." Methods 21(2): 185-97.

Yi, T., D. Zhao, et al. (2008). "Absence of donor Th17 leads to augmented Th1 differentiation and exacerbated acute graft-versus-host disease." Blood 112(5): 2101-10.

Yoshizawa, N., K. Yamakami, et al. (2004). "Nephritis-associated plasmin receptor and acute poststreptococcal glomerulonephritis: characterization of the antigen and associated immune response." J Am Soc Nephrol 15(7): 1785-93.

Yuan, H., E. Takeuchi, et al. (2002). "Nephrin dissociates from actin, and its expression is reduced in early experimental membranous nephropathy." J Am Soc Nephrol 13(4): 946-56. 


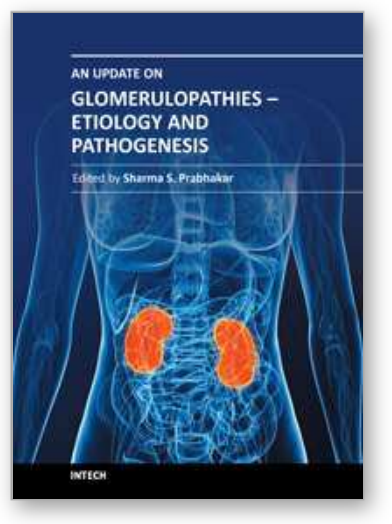

\author{
An Update on Glomerulopathies - Etiology and Pathogenesis \\ Edited by Prof. Sharma Prabhakar
}

ISBN 978-953-307-388-0

Hard cover, 276 pages

Publisher InTech

Published online 06, September, 2011

Published in print edition September, 2011

The book has fourteen chapters which are grouped under different sections: Immune System and Glomerulonephritis, Animal Models of Glomerulonephritis, Cytokines and Signalling Pathways, Role of Cells and Organelles in Glomerulonephritis and Miscellaneous. While the purpose of this volume is to serve as an update on recent advances in the etio-pathogenesis of glomerulopathies, the book offers the current and broad based knowledge in the field to readers of all levels in the nephrology community.

\title{
How to reference
}

In order to correctly reference this scholarly work, feel free to copy and paste the following:

Tetsuhiro Tanaka, William G Couser and Masaomi Nangaku (2011). The Role of Humoral and Cell-Mediated Adaptive Immune Response, An Update on Glomerulopathies - Etiology and Pathogenesis, Prof. Sharma Prabhakar (Ed.), ISBN: 978-953-307-388-0, InTech, Available from: http://www.intechopen.com/books/anupdate-on-glomerulopathies-etiology-and-pathogenesis/the-role-of-humoral-and-cell-mediated-adaptiveimmune-response

\section{INTECH}

open science | open minds

\section{InTech Europe}

University Campus STeP Ri

Slavka Krautzeka 83/A

51000 Rijeka, Croatia

Phone: +385 (51) 770447

Fax: +385 (51) 686166

www.intechopen.com

\section{InTech China}

Unit 405, Office Block, Hotel Equatorial Shanghai

No.65, Yan An Road (West), Shanghai, 200040, China

中国上海市延安西路65号上海国际贵都大饭店办公楼 405 单元

Phone: +86-21-62489820

Fax: $+86-21-62489821$ 
(C) 2011 The Author(s). Licensee IntechOpen. This chapter is distributed under the terms of the Creative Commons Attribution-NonCommercialShareAlike-3.0 License, which permits use, distribution and reproduction for non-commercial purposes, provided the original is properly cited and derivative works building on this content are distributed under the same license. 